SHORT REPORT

\title{
Sex differences in the experience of testing positive for genital chlamydia infection: a qualitative study with implications for public health and for a national screening programme
}

\author{
J Darroch, L Myers, J Cassell
}

Sex Transm Infect 2003;79:372-374

Objectives: To explore men's and women's accounts of chlamydia testing, with a view to understanding sex differences in attitudes and in behaviours of public health importance.

Methods: Semistructured interviews with 24 heterosexual patients (12 men; 12 women) diagnosed with genital chlamydia infection, at a large sexual health clinic in central London were transcribed and analysed using qualitative thematic analysis.

Results: Participants' expressions revealed important sex differences. Women felt anxious about their future reproductive health, feared stigmatisation, and blamed themselves for contracting chlamydia; whereas men generally reported less concern, were unwilling to disclose their condition to sexual partners, and some men projected attributions of blame onto their partners. Delays in seeking care appeared to be related to perceptions of chlamydia as a relatively minor infection, particularly in men.

Conclusions: Health promotion needs to reflect sex and age differences, emphasising the negative consequences of delayed clinic attendance and exposure to repeat infections. For health professionals to respond appropriately and effectively to increasing numbers of chlamydia infections, there is a need to understand men's avoidant attitudes and behaviours in relation to sexual and reproductive health.

$\mathrm{F}$ ollowing successful pilot chlamydia screening programmes in England, further screening sites have been announced. ${ }^{1}$ Chlamydia is a significant public health threat that affects both men and women. However, screening studies have, to date, focused on women. In order for effective prevention and control of the infection, there is a need to understand why both men and women seek medical attention, how they respond to their diagnosis, and whether sex differences exist. These issues are of particular importance, given that only a minority of those at risk attend clinics. $^{2}$

\section{METHODS}

The study setting was the Mortimer Market Centre (MMC), a busy sexual health clinic in central London.

An opportunistic sample of heterosexual patients with chlamydia was approached on the day of diagnosis or at follow up; $82 \%$ of those approached participated. The sample is described in table 1 .

Taped interviews were transcribed and identified themes were coded. Patients' data were matched to their clinical records. An independent author conducted an audit to ensure that interpretation is justified by the data. ${ }^{3}$

Camden and Islington Community NHS Trust's local research ethics committee approved the study.

\section{RESULTS}

The themes that emerged from the analysis are summarised in table 2 and discussed below.

\section{What is chlamydia?}

Despite reporting more chlamydia awareness than men, women considered their own vulnerability to contracting STIs to be low. Both men's and women's experience of previous STI testing was mixed; four women and two men had previously contracted chlamydia. The interviews revealed that most men, regardless of their experience of STI testing, failed to understand the nature of their infection. While men with more obvious symptoms sought care promptly, men with vague symptoms tried to ignore their symptoms, hoping that these would spontaneously resolve. Although no women correctly attributed their symptoms to a STI, interpreting these as being caused by "natural" changes, they generally sought medical care quicker than men with less obvious symptoms. Vague symptoms and/or being told by partners, as well as public health messages were not recognised by men as important enough triggers to seek immediate medical help. Worryingly, perceptions of low severity seemed to be related to reassuring health education intended to promote health.

" ...I knew it wasn't serious from the TV ad." (M10, asymptomatic male, notified by partner, delayed seeking treatment for 6 weeks)

\section{Initial reactions to diagnosis}

In an attempt to re-establish their personal status, some men and women took refuge in thinking that they could have been in a worse situation, projecting perceptions of stigma onto other STIs and HIV.

"...I thought at least it's chlamydia, it could have been something much worse, it could have been herpes, it could have been gonorrhoea... and that would be much worse so I'm glad, not glad but relieved...." (F4, asymptomatic female, notified by partner)

Others did not react in terms of being in shock or feeling relieved. This may have been influenced by a lack of knowledge. However, some men and women, with good knowledge, viewed chlamydia as a relatively minor infection, 


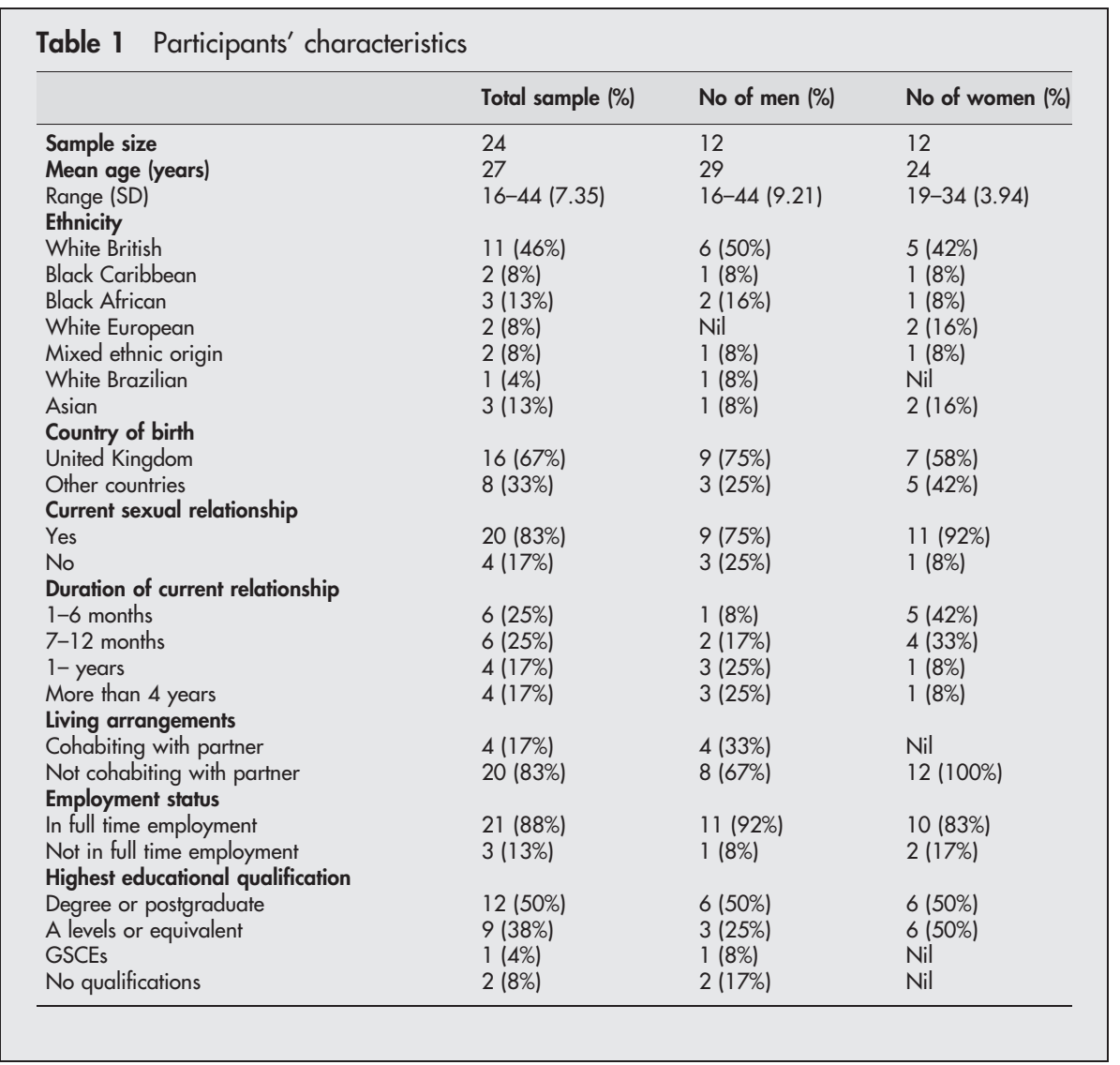

describing feeling reassured that any potentially adverse consequences could be eliminated by antibiotic treatment.

\section{Future fertility anxieties - a female concern}

Women expressed more anxieties than men about the potential effects of their infection on future fertility. Some women also requested further testing, expressing doubts about the efficacy of the treatment. These women felt worried that they may still be infected and this may affect their fertility, or that they would pass the infection onto their partners. The information provided did not allay fertility worries, with residual anxieties and self blame remaining prominent in some women's accounts. In contrast with women's anxieties about their future reproductive health, only a few men reported an awareness of the association between chlamydia and infertility.

\section{Overcoming partner notification fears}

Men and women differed in their attributions of blame. Women tended to assume responsibility for passing chlamydia onto partners, expressing guilt and self punishment within this context. In contrast, men either blamed partners for the infection or did not exhibit self blame. Women reported fears about their partners' negative responses and potential threats to their relationships. Some women also experienced blame or denial of the infection from their partners.

".....he says it's not him but l've not slept with anyone else, he's the only one. I'd never slept with anyone before but I've finished with him now after hearing that. Yeah I was very upset. I spoke to him on the phone but he just kept saying he didn't have it, it wasn't from him." (F10, symptomatic female)
Table 2 Main themes and subthemes derived from analysis of interview transcripts

What is chalmydia?

- Lack of awareness, especially men

- Perceptions of low susceptibility to STIs (women)

- Perceptions of low severity, particularly in men

- Complex health beliefs - entwined with emotions about relationship

- Uncertainty about duration of infection

- Misinterpretation of symptoms

- Delaying seeking help

- Using STI check ups as perceived prevention

- Vague symptoms and partner notification not perceived as important cues (men)

- Severity of symptoms related to support and prompt care seeking (men)

Initial reactions to diagnosis

- Mixed reactions

- Shock and uncertainty

- Feelings of stigmatisation (women)

- Feeling isolated, unwilling to tell others in support network (women)

- Relief-alerted to unknown threat

- Relief-downward comparisons to other STIs

- Ambivalence-chlamydia seen as relatively minor, curable infection

Anxieties about future reproductive health $-\mathrm{a}$ female concern

- Anxieties about future fertility (mostly women)

- Guilt and self punishment for not seeking earlier care (women)

- Fears exacerbated by uncertainty of duration of infection

- Anxieties not allayed by information

- Low personal control- "in hands" of medical staff

- Only small number of men reported an awareness of the association between chlamydia and infertility

- Most men did not report worries about future reproductive health Overcoming partner notification fears

- Fear of partners' negative responses and threat to current relationship

- Attributions of blame-self blame (women), blamed partners (men)

- Grateful to health advisers for partner notification support

- Notifying partners themselves rather than clinical referral

- Avoiding partner communication (men)

- Relief when partners told 
Men also felt worried and embarrassed about telling partners, reporting an avoidance of disclosing their condition to their partners either by not seeing them or by relying on their partners to "read between the lines." Despite initial concerns, and men's reluctance to tell their partners, partner notification fears were generally overcome with help from clinic health advisers, and most men and women chose to inform their partners themselves, rather than through clinic referral, which led to feelings of relief.

\section{DISCUSSION}

Our study has shown important sex differences in these participants' experiences of chlamydia testing. In particular, men's responses indicated generally avoidance attitudes and behaviours. The concerns expressed by women about future reproductive health and partner notification fears in our study reflect those reported in other research, ${ }^{4}$ which did not include men. In contrast to women's expressions of self blame and protective attitudes towards their partners' sexual health, some men attributed blame to their female sexual partners. The supportive role of the health adviser was especially important in encouraging men to overcome their unwillingness to inform their sexual partners about their infection. Our findings show how little views about sexuality and sexual health have moved away from the concept of the blameless male and the stigmatised women, highlighting that more health promotion efforts specifically focusing on men's attitudes and behaviours are needed to address attributions of blame and stigmatisation.

Men's avoidant attitudes were also manifested in their reluctance to respond to vague genital symptoms, despite some men also being informed by their partners of a potential chlamydial infection. While spontaneous resolution may be encouraged in other medical contexts (for example, backache), our findings suggest that health education should highlight the importance of seeking prompt medical attention for minor genital symptoms. While our sample was diverse and from different age groups, most participants were generally older than those considered to be at risk from contracting chlamydia, and relatively well educated, therefore not necessarily representative. However, this study shows that a diagnosis of chlamydia means different things to different people. A greater understanding of both men's and women's responses to chlamydial infection is needed before the implementation of a national screening programme, which will focus almost exclusively on women.

\section{ACKNOWLEDGEMENTS}

We thank all study participants for sharing their experiences and for their time, we also thank Eva Jungmann for help in enlisting the support of clinical staff and all clinical staff at the Mortimer Market Centre who contributed to the research. Thanks also to Poala Nunziata for the independent audit of the data analysis.

\section{CONTRIBUTORS}

JD had the original idea for the project, was principal investigator, and is guarantor; JD conducted, transcribed, and analysed the interviews; LM and JC advised on the study's design, supervised data collection, and analysis; PN conducted the audit of the analysis. All authors contributed towards writing the paper and approved the final version.

\section{Authors' affiliations}

J Darroch, L Myers, Royal Free and University College Medical School, Department of Psychiatry and Behavioural Sciences, (Bloomsbury Campus and Whittington Campus), Wolfson Building, 48 Riding House Street, London WIN 8AA, UK

J Darroch, J Cassell, Royal Free and University College Medical School, Department of Sexually Transmitted Diseases, Mortimer Market Centre, 4th Floor, Off Capper Street, London WCIE 6AU, UK

Correspondence to: Dr Lynn Myers, Royal Free and University College Medical School, Department of Psychiatry and Behavioural Sciences, (Bloomsbury Campus and Whittington Campus), Wolfson Building, 48 Riding House Street, London WIN 8AA, UK; I.myers@ucl.ac.uk

Accepted for publication 20 March 2003

\section{REFERENCES}

1 Department of Health. The national strategy for sexual health and HIV. London: DoH, 2001.

2 Johnson AM, Wadsworth J, Wellings $\mathrm{K}$, et al. Who goes to sexually transmitted disease clinic? Results from a national population survey. Genitourin Med 1996;72:197-202.

3 Yin R. Case study research: designs and methods. Newbury Park, CA: Sage, 1989.

4 Duncan B, Hart G, Scoular A, et al. Qualitative analysis of psychosocial impact of diagnosis of Chlamydia trachomatis: implications for screening. BMJ 2001;322:195-9. 